\title{
Aspergillus galactomannan detection in comparison to a real-time PCR assay in serum samples from a high-risk group of patients
}

\author{
EWA SWOBODA-KOPE $C^{1}$, MARLENA GOEAS ${ }^{\prime}$, KATARZYNA PISKORSKA ${ }^{l}$, \\ MARIA DĄBKOWSKA ${ }^{1}$, IRENA NIECWIETAJEWA ${ }^{1}$, LESZEK PĄCZEK ${ }^{2}$, MAGDALENA SIKORA $^{3,4}$ \\ ${ }^{1}$ Department of Medical Microbiology, Medical University of Warsaw, Warsaw, Poland \\ ${ }^{2}$ Department of Immunology, Transplantology and Internal Medicine, Institute of Transplantology, Medical University of Warsaw, \\ Warsaw, Poland \\ ${ }^{3}$ Department of Dental Microbiology, Medical University of Warsaw, Warsaw, Poland \\ ${ }^{4}$ Department of Medical Microbiology, The Infant Jesus Teaching Hospital (IJTH) in Warsaw, Warsaw, Poland
}

\begin{abstract}
Invasive aspergillosis (IA) is a severe infection with a $70 \%$ mortality rate. Aspergillus fumigatus is responsible for over $90 \%$ of those infections.

The diagnosis of invasive aspergillosis is based on clinical sample culture and detection of fungal hyphae in histopathological examination. Additional tests may include the detection of the galactomannan antigen and of fungal genetic material in serum and bronchoalveolar washings. The present study was to assess the use of these two rapid tests in the diagnosis of invasive aspergillosis: serological one - to detect the galactomannan antigen (ELISA assay), and real-time PCR, and to establish a possible correlation between these two methods.
\end{abstract}

Key words: Aspergillus, real-time PCR, galactomannan, aspergillosis, Mycassay ${ }^{T M}$.

(Cent Eur J Immunol 2015; 40 (4): 454-460)

\section{Introduction}

Invasive aspergillosis (IA) has one of the highest mortality rates in patients under immunosuppressive treatment. Mainly post bone marrow or solid organ transplant patients treated for blood cancer are at high risk. Early detection is crucial in adequate therapy implementation [1].

Invasive aspergillosis diagnosis is a challenge as the infection presents a low radiographic sensitivity and no specific clinical signs. According to 2008 EORTC/MSG guidelines, an abnormal computed tomography (CT) scan is required to detect or rule out invasive infections. In the case of a normal CT scan, microbiological tests and host risk factors are not enough to diagnose invasive infections [2]. Abnormal X-rays do not make it possible to identify specific pathogens, and a biopsy is most often not a viable option in patients undergoing chemotherapy. Among infectious biological markers, testing for galactomannan in serum is the only sufficiently explored technique that can be used. The use of these markers in tissues other than peripheral blood increases galactomannan detection, especially when bronchoalveolar lavage (BAL) can be performed. Classical microbiological diagnostics, including pathogen culture and microscopic analysis of respiratory tract samples, cannot unambiguously confirm or rule out infections $[1,3]$. Non-culture methods, such as detecting fungal cell wall components - galactomannan antigens and $1,3-\beta$-D-glucan circulating in serum, and BAL, are useful in the diagnosis of invasive aspergillosis, but also limited by false positive or negative results related to many factors [3]. False positive results might be a consequence of the use of B-lactam antibiotic (piperacillin with tazobactam), cyclophosphamide, immunoglobulin, plasma-like products, or hydrating fluid containing galactomannan. Cases of cross reactions in patients infected with other fungal species (Penicillium sp., Paecilomyces sp., or Fusarium) or with Bifidobacterium sp. were also reported [1, 4-6]. Despite their limitations, commercial serological tests detecting cell wall components of yeast-like fungi, are widely used in diagnostics [7].

Progress in molecular biology made it possible to start diagnosing IA with PCR assay [7]. These tests identify the pathogen type or species in a fairly short time, without having to perform invasive procedures on patients (biopsy) [3]. Despite a vast diversity and availability of commercial tests, their use in IA diagnosis is limited because they are not standardized $[1,8]$. Badiee et al. assessed, while

Correspondence: Katarzyna Piskorska, MSc, Department of Medical Microbiology, Medical University of Warsaw, Chałubińskiego 5, 02-004 Warsaw, e-mail: kaspiskorska@gmail.com 
comparing classical diagnostic techniques with PCR, the sensitivity, specificity, positive and negative PCR results at $86.6 \%, 82 \%, 96.5 \%$, and $52 \%$, respectively [9]. Real-time PCR is a modification of standard PCR. This assay delivers faster results than classical PCR. The high sensitivity and specificity of real-time PCR in diagnosing invasive aspergillosis was reported in other studies [10-21]. MycAssay ${ }^{\mathrm{TM}}$ is the only available commercial test detecting Aspergillus DNA in serum or BAL (Myconostica, currently Lab21 Company, Cambridge, UK). This test was designed to detect genomic DNA of 18 Aspergillus species, including A. fumigatus, A. flavus, A. terreus, and A. niger, using molecular beacon probes detecting $18 \mathrm{~S}$ rRNA genes [8, 22].

\section{Study objective}

The study was to compare the clinical usefulness of the commercially available MycAssay ${ }^{\mathrm{TM}}$ in patients at higher risk of pulmonary aspergillosis with positive or negative galactomannan antigen levels.

\section{Material and methods}

Twenty patients suspected of IA, including three patients after their first kidney transplant, five patients preparing for a subsequent kidney transplant, and 11 patients post liver transplant, were included in the study. Serum samples, collected from patients during routine diagnostics, were first tested for the galactomannan antigen with the ELISA assay. Later on, the samples, kept at $-20^{\circ} \mathrm{C}$, were tested with MycAssay ${ }^{\mathrm{TM}}$ to establish a possible correlation between the two methods. Forty five serum samples from 20 patients ( 12 females and 8 males aged beetwen 23 and 90), suspected of IA and treated at the Medical University of Warsaw, Institute of Transplantology, were tested for galactomannan. None of the patients was following a treatment described by the producer as potentially inhibiting PCR. Serum samples to be tested were retrospectively selected according to their availability, IA clinical symptoms in patients, and clinical sample culture results.

\section{GM PLATELIA Aspergillus}

Sandwich ELISA to detect galactomannan in serum was performed following the producer's guidelines [23] (Platelia Aspergillus protocol: Bio-Rad, Marnes-la-Coquette, France). Optical density (OD) was measured spectrophotometrically with Bio-Rad Model PR5100 ELISA microplate reader (Bio-Rad, Marnes-la-Coquette, France). Results were interpreted based on the index calculated from the measured OD, using a $450 \mathrm{~nm}$ wavelength. Indexes $\geq 0.5$ were considered positive.

The isolation of total genomic DNA was performed with the High Pure PCR Template Preparation Kit (Roche, Mannheim, Germany). Aspergillus fumigatus ATCC
204305 was the reference strain used to control DNA isolation. MycAssay ${ }^{\mathrm{TM}}$, real-time PCR assay (Myconostica, currently Lab21, Cambridge, UK), was used, according to the producer's guidelines, to test for Aspergillus spp. specific gene in serum. Purified DNA was assayed with Real-Time PCR for targeted Aspergillus 18S rRNA gene. For every analysed sample, $10 \mu \mathrm{l}$ of purified DNA were used together with reaction mixtures, totalling to a final volume of $25 \mu \mathrm{l}$. Negative and positive control reactions were also conducted. The MycAssay ${ }^{\mathrm{TM}}$ protocol includes the following reaction controls: internal amplification, and negative and positive controls. Furthermore, the DNA previously isolated from Aspergillus fumigatus ATCC 204305 served as a positive control. Samples with a $\mathrm{Cp}<38$ were considered positive. The crossing point $(\mathrm{Cp})$ was the cycle number at which the real-time PCR test became positive. Samples with a $\mathrm{Cp} \geq 38$ or with zero crossing points were considered negative. White et al. study, sponsored by Myconostica, on serum samples from 18 healthy individuals was used as control group [24].

\section{Results}

Serum samples from patients suspected of IA, including positive and negative galactomannan antigen levels, were tested. The results of serological and genetic tests, mycological cultures, CT scans and X-rays were all taken into account. Study results are presented in Tables 1 and 2 . Table 1 presents the results of eight serum samples from seven patients suspected of IA.

MycAssay ${ }^{\mathrm{TM}}$ confirmed the infection in four patients (around 50\%) among those whose serum tested positive for galactomannan.

MycAssay ${ }^{\mathrm{TM}}$ did not detect any DNA of Aspergillus spp. in patient no. 2 despite a positive result for circulating antigens. Their transaminase level was normal.

Also for patients no. 6 and 7 with a positive glactomannan antigen no Aspergillus DNA was detected. No yeast-like Aspergillus fungi were cultured from patient no. 6, however Aspergillus fumigatus was cultured from BAL samples of patient no. 7. Both patients had elevated transaminase levels.

Table 2 presents the results of 37 serum samples from 13 patients suspected of IA with negative galactomannan antigen levels.

In four (no. 9, 10, 17, and 20) out of 13 patients, MycAssay $^{\mathrm{TM}}$ detected Aspergillus DNA in all cultured serum samples. All patients had normal transaminase levels.

Patients no. 11, 12, 13, and 14 were suspected of pulmonary aspergillosis basing on their X-rays. MycAssay ${ }^{\mathrm{TM}}$ tested positive in one of the two serum samples in all of the above-mentioned patients. They had normal transaminase levels.

Patient no. 8 had proven pulmonary aspergillosis based on CT scan and X-ray results and an elevated transaminase 


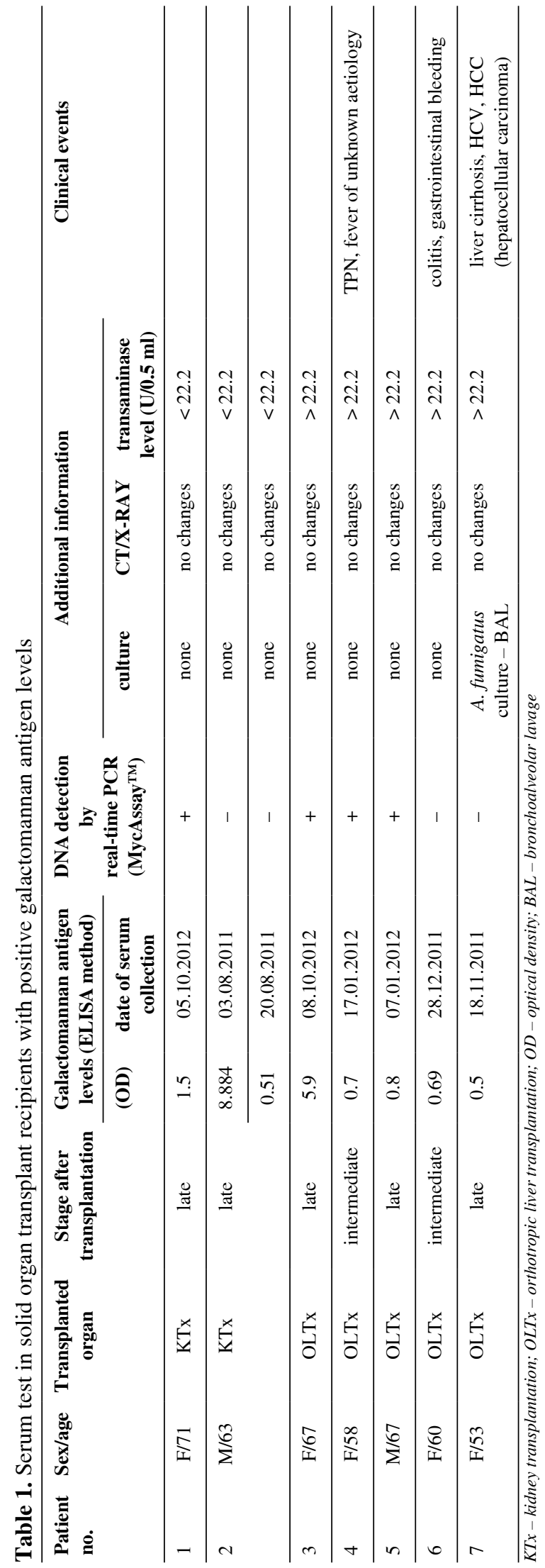

level. MycAssay ${ }^{\mathrm{TM}}$ detected Aspergillus DNA only in one of the three collected serum samples.

Patients no. 16 and 17 had elevated transaminase levels but no changes were visible in X-ray imaging. In these patients MycAssay ${ }^{\mathrm{TM}}$ delivered amibiguous results - some samples from the same patients gave positive and others - negative results.

The real-time PCR results of patients no. 15 and 19, suspected of aspergillosis based on their $\mathrm{CT}$ and $\mathrm{X}$-ray results and having elevated transaminase levels, were amibiguous. Aspergillus DNA was detected in three out of 9 serum samples in patient no. 15 . However, for patient no. 19 only one sample out of three tested positive.

\section{Discussion}

Invasive fungal infections are a serious complication, especially in solid organ transplant patients. In this group, fungal infections represent about 5\% of all infections [25] and present a high mortality rate.

They are also extremely hard to detect. They do not present any specific clinical signs, lesions (especially in Aspergillus infections) are often encapsulated, which makes it more difficult to culture aetiological agents. There are no standardised techniques that would allow a rapid and early detection of invasive infections, which is also problematic. Galactomannan detection in blood serum and bronchoalveolar washings are one of the useful tests in diagnosing Aspergillus infections. Platelia Aspergillus (BioRad, Marnes-la-Coquette, France) is the galactomannan antigen detection assay used in vitro.

Early diagnosis of Aspergillus spp. infections remains a great challenge, and with the development of molecular techniques, scientists focus on finding reliable solutions to detect Aspergillus spp. DNA in clinical samples [21]. The have recently introduced an assay, detecting Aspergillus spp. DNA with real-time PCR assay, which is a supplement to classical mycological diagnosis. This technique is very sensitive to and specific in aetiological agent detection (sensitivity and specificity of $94 \%$ and $77 \%$, respectively, with positive and negative predictive results at $91 \%$ and $83 \%$ ) [22]. The study was to assess the clinical effectiveness of MycAssay ${ }^{\mathrm{TM}}$ in patients at a higher risk of pulmonary aspergillosis with positive or negative galactomannan antigen levels.

Despite the high sensitivity of the assay, the elements that might have a negative impact on its results are worth noting. The level of transaminases in patients, which at $22.2 \mathrm{U} / 0.5 \mathrm{ml}$ in serum might cause Aspergillus DNA to degrade, is crucial and might result in a false negative result. In the group with positive galactomannan levels, false negative results, a consequence of high aminotransferase levels, could be obtained in patients no. 6 and 7; whereas in the group with negative galactomannan levels, in patients no. $8,15,16,18$, and 19 . It is also critical that serum 


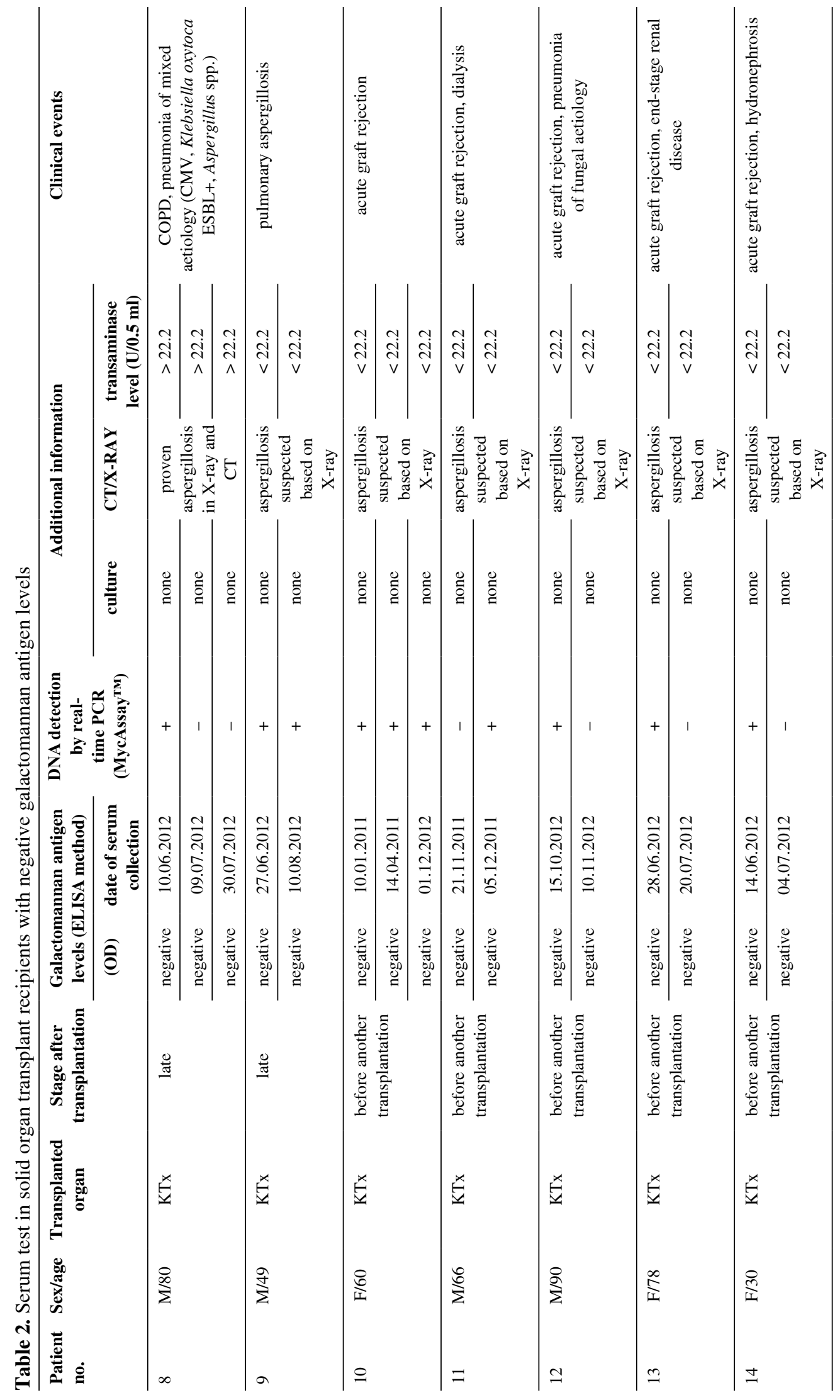




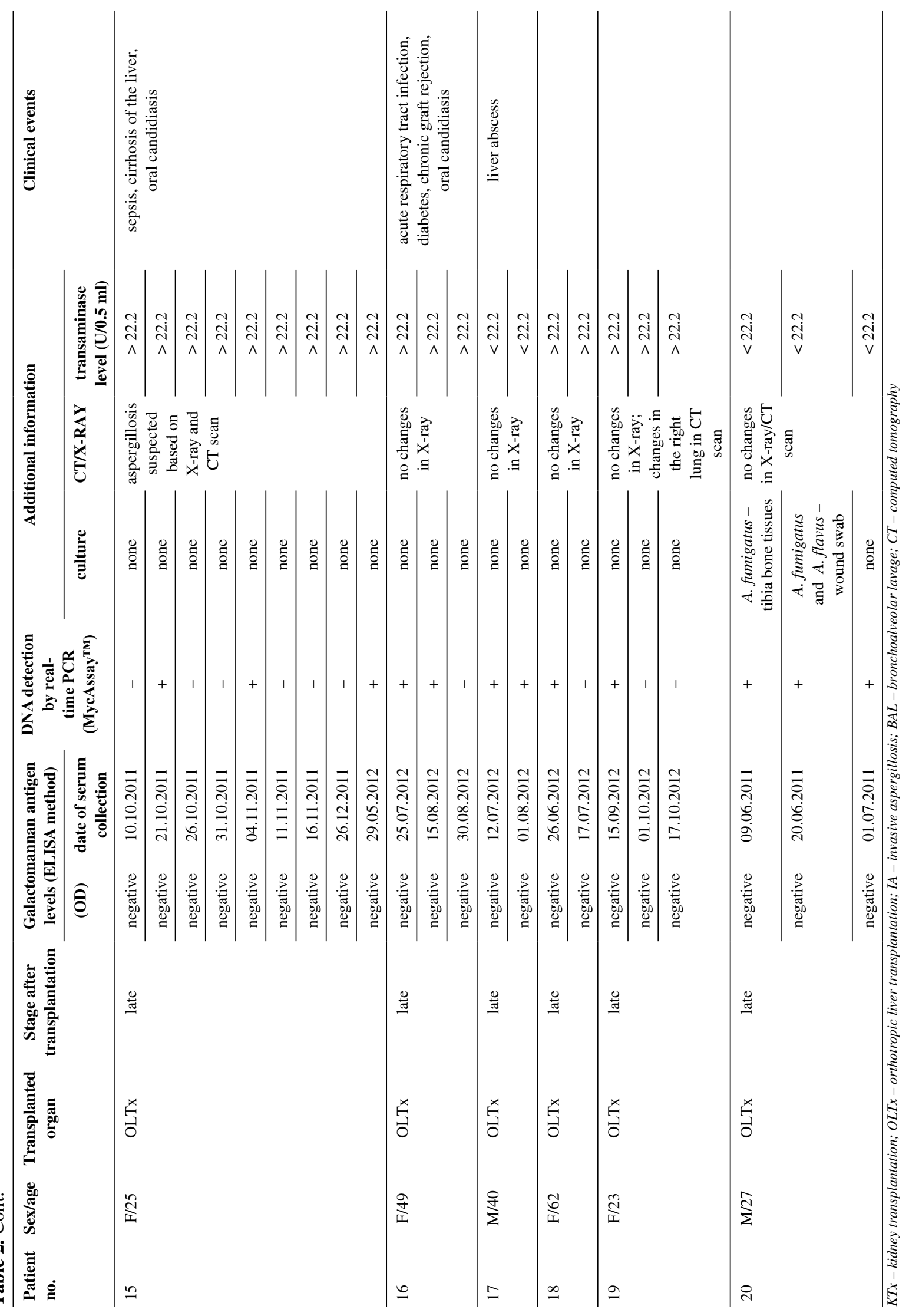


be stored appropriately before testing. The present study was a retrospective serum assessment, therefore sample storage could have affected DNA degradation and lead to false negative results. The retrospective study was carried out in 2012. Too long or inappropriate sample storage might result in DNA degradation. Morton et al. pointed out that Aspergillus DNA was stable in blood serum only for a relatively short period of time $<144 \mathrm{~h}$ [26]. This could result in false results. Clinical factors (Aspergillus colonisation) and factors related to clinical sample preparation (Aspergillus airway contamination, PCR product contamination with another sample, and cross-reactivity between starters, probes, and the genetic material of other fungal species) could result in false positive results. White et al. study, sponsored by the MycAssay ${ }^{\mathrm{TM}}$ producer, was carried out on a group of generally healthy individuals. One out of 18 samples tested positive and therefore the study was repeated at an independent centre. The repeated study did not confirm the positive result. The serum sample contamination was stated as the reason behind the falsely positive result [24].

MycAssay ${ }^{\mathrm{TM}}$ Aspergillus $\mathrm{PCR}$ presents major cross-reactivity with most Penicillium spp. species, which rarely cause opportunistic infections in humans. On the other hand, galactomannan might even more often cross-react with Penicillium spp. or Paecilomyces spp. antigens.

Torelli et al. reported some patients who were colonised by Aspergillus but presented a negative galactomannan result in BAL samples assayed with ELISA. They assessed the specificity of this technique at $92 \%$ vs. 50\% for Aspergillus DNA detection. They also pointed out that galactomannan needed to be detected earlier, and DNA detection should only confirm IA and improve the specificity of the results [1]. The same could have occurred in the present patients no. 9, 10, 17, and especially 20, out of whose samples A. fumigatus was cultured twice. White et al. stated that for Aspergillus PCR, it was technically better to sample serum instead of full blood. Both tests, galactomannan and PCR, could be performed on a single serum sample, enabling result comparison, which was beneficial for patients [24]. MycAssay ${ }^{\mathrm{TM}}$ might be compared to the commercial PCR assay and to galactomannan tests, previously introduced to IA diagnostics. It is necessary to conduct prospective tests on MycAssay ${ }^{\mathrm{TM}}$ effectiveness in IA diagnostics. Such a study would increase the clinical significance of the assay and limit DNA degradation.

Only the clinical picture, CT scan, clinical sample culture, and confirmation with one of the following methods - ELISA (serological) or MycAssayTM (genetic) should be decisive. It seems that negative results of serological and genetic tests, together with negative results of other tests, should rule out invasive aspergillosis. A positive MycAssay ${ }^{\mathrm{TM}}$ result in more than one serum sample and with infection symptoms, such as fever of unknown origin, abnormal CT, absence of clinical sample cultures, should be treated as potential IA. Such patients should be closely monitored and tested for invasive aspergillosis (e.g. patients no. 9, 10, 16, 17, and 20).

The present study revealed that both galactomannan antigen testing and the real-time PCR assay (MycAssay ${ }^{\mathrm{TM}}$ ) were useful, however, the absence of any correlation between the two methods could neither confirm nor rule out IA. Such an assay should be used for secondary testing when invasive aspergillosis was suspected, galactomannan antigen detected, or Aspergillus spp. cultured.

The authors declare no conflict of interest.

The study was financed by the National Centre for Science (Grant no. N N401 042738). Project manager: E. Swoboda-Kopeć, $M D, P h D$.

\section{References}

1. Torelli R, Sanguinetti M, Moody A, et al. (2011): Diagnosis of invasive aspergillosis by a commercial real-time PCR assay for Aspergillus DNA in bronchoalveolar lavage fluid samples from high-risk patients compared to a galactomannan enzyme immunoassay. J Clin Microbiol 49: 4273-4278.

2. Agrawal S, Hope W, Sinkó J, Kibbler C (2011): Optimizing management of invasive mould diseases. J Antimicrob Chemother 66 Suppl 1: i45-53.

3. Hadrich I, Mary C, Makni F, et al. (2011): Comparison of PCR-ELISA and Real-Time PCR for invasive aspergillosis diagnosis in patients with haematological malignancies. Med Mycol 49: 489-494.

4. Cuenca-Estrella M, Bassetti M, Lass-Flörl C, et al. (2011) Detection and investigation of invasive mould disease. J Antimicrob Chemother 66 Suppl 1: i15-24.

5. Fortún J, Martín-Dávila P, Alvarez ME, et al. (2009): False-positive results of Aspergillus galactomannan antigenemia in liver transplant recipients. Transplantation 87(2): 256-260.

6. Witalis J, Filipek B (2012): Leczenie inwazyjnych i powierzchniowych zakażeń grzybiczych. Farmacja Szpitalna 1: 5-14.

7. Rogers TR, Morton CO, Springer J, et al. (2013): Combined real-time PCR and galactomannan surveillance improves diagnosis of invasive aspergillosis in high risk patients with haematological malignancies. Br J Haematol 161: 517-524.

8. Guinea J, Padilla C, Escribano P, et al. (2013): Evaluation of MycAssay ${ }^{\mathrm{TM}}$ Aspergillus for diagnosis of invasive pulmonary aspergillosis in patients without hematological cancer. PLoS One 8: e61545.

9. Badiee P, Alborzi A (2010): Detection of Aspergillus species in bone marrow transplant patients. J Infect Dev Ctries 4: 511-516.

10. de Aguirre L, Hurst SF, Choi JS, et al. (2004): Rapid differentiation of Aspergillus species from other medically important opportunistic molds and yeasts by PCR-enzyme immunoassay. J Clin Microbiol 42: 3495-3504.

11. Einsele H, Hebart H, Roller G, et al. (1997): Detection and identification of fungal pathogens in blood by using molecular probes. J Clin Microbiol 35: 1353-1360. 
12. Faber J, Moritz N, Henninger N, et al. (2009): Rapid detection of common pathogenic Aspergillus species by a novel real-time PCR approach. Mycoses 52: 228-233.

13. Hendolin PH, Paulin L, Koukila-Kähkölä P, et al. (2000): Panfungal PCR and multiplex liquid hybridization for detection of fungi in tissue specimens. J Clin Microbiol 38: 4186-4192.

14. Kami M, Fukui T, Ogawa S, et al. (2001): Use of real-time PCR on blood samples for diagnosis of invasive aspergillosis. Clin Infect Dis 33: 1504-1512.

15. Kawazu M, Kanda Y, Nannya Y, et al. (2004): Prospective comparison of the diagnostic potential of real-time PCR, double-sandwich enzyme-linked immunosorbent assay for galactomannan, and a (1-->3)-beta-D-glucan test in weekly screening for invasive aspergillosis in patients with hematological disorders. J Clin Microbiol 42: 2733-2741.

16. Klingspor L, Loeffler J (2009): Aspergillus PCR formidable challenges and progress. Med Mycol 47 Suppl 1: S241-247.

17. Loeffler J, Henke N, Hebart H, et al. (2000): Quantification of fungal DNA by using fluorescence resonance energy transfer and the light cycler system. J Clin Microbiol 38: 586-590.

18. Sanguinetti M, Posteraro B, Pagano L, et al. (2003): Comparison of real-time PCR, conventional PCR, and galactomannan antigen detection by enzyme-linked immunosorbent assay using bronchoalveolar lavage fluid samples from hematology patients for diagnosis of invasive pulmonary aspergillosis. J Clin Microbiol 41: 3922-3925.

19. Suarez F, Lortholary O, Buland S, et al. (2008): Detection of circulating Aspergillus fumigatus DNA by real-time PCR assay of large serum volumes improves early diagnosis of invasive aspergillosis in high-risk adult patients under hematologic surveillance. J Clin Microbiol 46: 3772-3777.

20. Van Burik JA, Myerson D, Schreckhise RW, Bowden RA (1998): Panfungal PCR assay for detection of fungal infection in human blood specimens. J Clin Microbiol 36: 1169-1175.

21. Wengenack NL, Binnicker MJ (2009): Fungal molecular diagnostics. Clin Chest Med 30: 391-408.

22. Myconostica L (2010): MycAssay Aspergillus Roche LightCycler 2.0 Serum Instruction for use REF 080-045. Version 1.0. Myconostica Manchester, United Kingdom.

23. BioRad (2013): PLATELIA Aspergillus. Instruction for use Cat no. 62794. Bio-Rad, Marnes-la-Coquette, France.

24. White PL, Perry MD, Moody A, et al. (2011): Evaluation of analytical and preliminary clinical performance of Myconostica MycAssay Aspergillus when testing serum specimens for diagnosis of invasive Aspergillosis. J Clin Microbiol 49: 2169-2174.

25. Nabili M, Shokohi T, Janbabaie G, et al. (2013): Detection of invasive aspergillosis in bone marrow transplant recipients using real-time PCR. J Glob Infect Dis 5: 68-75.

26. Morton CO, Loeffler J, De Luca A, et al. (2010): Dynamics of extracellular release of Aspergillus fumigatus DNA and galactomannan during growth in blood and serum. J Med Microbiol 59 (Pt 4): 408-413. 